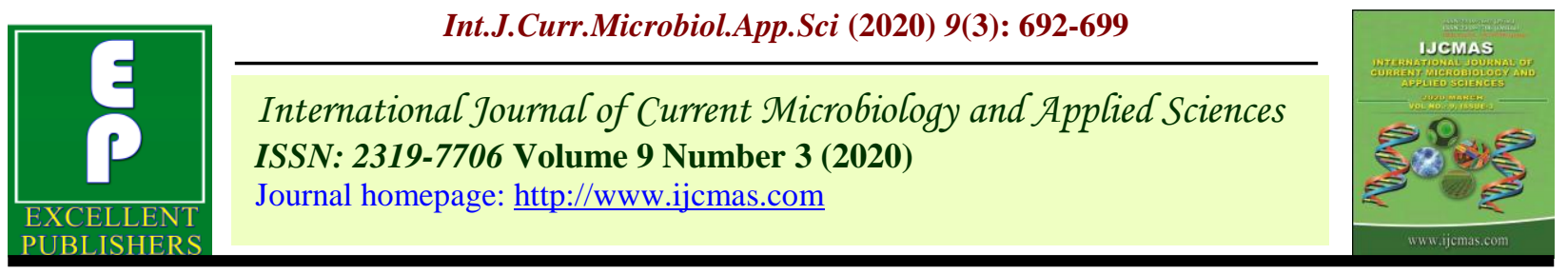

Original Research Article

https://doi.org/10.20546/ijcmas.2020.902.083

\title{
Inhibitory Potential Assessment of Silver Nanoparticle on Phytopathogenic Spores and Mycelial Growth of Bipolaris sorokiniana and Alternaria brassicicola
}

\author{
Aakanksha Kriti ${ }^{1}$, Abhijeet Ghatak ${ }^{1} *$ and Nintu Mandal ${ }^{2}$ \\ ${ }^{1}$ Department of Plant Pathology, Bihar Agricultural University, \\ Sabour, Bhagalpur, Bihar, India \\ ${ }^{2}$ Department of Soil Science and Agricultural Chemistry, Bihar Agricultural University, \\ Sabour, Bhagalpur, Bihar, India \\ *Corresponding author
}

\section{A B S T R A C T}

\begin{tabular}{|l|}
\hline Key w or d s \\
AgNP, Alternaria \\
brassicicola, \\
Bipolaris \\
sorokiniana, \\
Nanoparticle
\end{tabular}

Inhibitory potential of silver nanoparticle $(\mathrm{AgNP})$ at concentrations of 10, 20, 50 and $100 \mathrm{ppm}$ was assessed on two foliar phytopathogens viz. Bipolaris sorokiniana and Alternaria brassicicola. Antifungal activity of AgNP was found to be significant in reducing germinating spores as well as mycelial growth of both pathogens in an experiment under controlled condition. AgNP at a concentration of $20 \mathrm{ppm}$ was found effective to inhibit spore germination in B. sorokiniana as well as A. brassicicola. AgNP at $100 \mathrm{ppm}$ resulted in restricting maximum mycelial growth for both pathogens. Hence, the current work revealed to apply 20 ppm of AgNP if considering a greater reduction in germinating spores of $B$. sorokiniana and A. brassicicola. Further, $100 \mathrm{ppm}$ of AgNP may be preferred in restricting mycelial growth for these pathogens. The study, therefore, indicates that AgNP is having significant antifungal activity against $B$. sorokiniana and $A$. brassicicola, and hence, may find its scope in inhibiting the growth of foliar fungal pathogens (Deuteromycota) paving way for future experimental work in the field of plant disease management.

\section{Introduction}

Silver is known since a very long period as an element with the antimicrobial property. Over millennium, it is widely used as a food additive to keep the food for a longer time without microbial spoilage and also has seen to possess antibacterial property (Crede,
1881). Recently, nano-silver is utilised in the field of plant pathological studies. Widespread use of chemical fungicides has already caused ecological imbalance leading to deteriorating impact on beneficial flora and fauna as well as the development of resistant pathogens (Lamsal et al., 2011; Ouda, 2014). In order to evade such situations which may 
have several times negative impact on soil, plant and ecological health with an increasing use of chemical fungicides in controlling plant disease, there arises an urgent need for an alternative method of managing phytopathogens. The antifungal activity of silver nanoparticle (AgNP) has been noticed on Magnaporthe grisea and Bipolaris sorokiniana (Gajbhiye et al., 2009), Rhizoctonia solani, Sclerotinia sclerotiorum and Sclerotium minor (Min et al., 2009). AgNP exhibits rapid chemical reactivity due to its higher surface area leading to disruption of several biological functions in microbes. This property of AgNP may be utilised in controlling the growth of pathogens. The future of AgNP resides with the present investigations on testing its antimicrobial activity on phytopathogenic sporulation as well as mycelial growth of fungus.

Bipolaris sorokiniana and Alternaria brassicicola are the two such sporulating foliar phytopathogens which may provide new scope for the inhibitory potential of AgNP. Any change in the regular spore germination capacity of these pathogens on AgNP application may signify the potential ability of AgNP to employ in the field of fungal disease management. Further, in vitro experiment on mycelial growth of the fungi on the application of AgNP may suggest its applicability in restricting growth of pathogens. The current work was thus targeted to assess the potential ability of AgNP to reduce sporulation and mycelial growth of fungal pathogens, $B$. sorokiniana and A. brassicicola.

\section{Materials and Methods}

Isolates of B. sorokiniana and A. brassicicola were collected from infected barley and mustard crops, respectively from Agricultural Farm of Bihar Agricultural University, Sabour. The specimen was washed under running tap water, cut into small pieces, again rinsed thrice with $1 \%$ sodium hypochlorite solution for 1 minute and finally washed with distilled water for three times under aseptic condition. Thereafter, the specimens were transferred onto PDA plates, allowed to grow for 2-3 days, and incubated at $25 \pm 1^{\circ} \mathrm{C}$. Fungal mycelium from the edge was transferred to PDA slants, grown for 5-6 days in the incubator at $25 \pm 1^{\circ} \mathrm{C}$ and stored at $4^{\circ} \mathrm{C}$ in a refrigerator. Isolates were maintained and subsequently used in the experiment whenever required.

Four different concentrations of AgNP were prepared by diluting the initial concentration of $100 \mathrm{ppm}$ solution. AgNP was synthesized by chemical reduction method (Ratyakshi and Chauhan, 2009). Silver nitrate $\left(\mathrm{AgNO}_{3}\right)$ and tri-sodium citrate $\left(\mathrm{C}_{6} \mathrm{H}_{5} \mathrm{O}_{7} \mathrm{Na}_{3}\right)$ of analytical grade purity (Advance Inorganics pvt ltd) without further purification were used as starting materials. Silver nitrate $(50 \mathrm{ml}$, $0.001 \mathrm{M})$ was heated till boiling. To this solution, $5 \mathrm{ml}$ of $1 \%$ tri-sodium citrate was added drop by drop with vigorous mixing. The solution was again heated till colour changed to pale yellow, removed from heating and stirred until attained room temperature. $\mathrm{AgNP}$ in the range of $25-32 \mathrm{~nm}$ was obtained using transmission electron microscopy (TEM).

Effect of nanoparticle on spore germination percent was tested by preparing conidial suspension of 15-20 days old cultures of both pathogens in $0.025 \%$ Tween 20 solution (Ghatak et al., 2013). Conidial suspension of different concentrations of AgNP (viz. 10, 20, 50 and $100 \mathrm{ppm}$ ) was prepared and placed over the cavity. Conidial suspension in Tween20 without AgNP was treated as control. The spore suspension containing cavity slides were incubated at $25 \pm 1^{\circ} \mathrm{C}$ for 24 $\mathrm{h}$ (B. sorokiniana) and $48 \mathrm{~h}$ (A. brassicicola) in moist chambers developed with Petriplates 
(90 $\mathrm{mm}$ diameter) containing blotter papers soaked in sterile distilled water. The slides were examined under a microscope (40x, Olympus). Similarly, the efficacy of AgNP on mycelial growth of $B$. sorokiniana and $A$. brassicicola was observed by conducting poisoned food assay. The comparison was made with the control with no use of the inhibitory chemical. Actively growing mycelium (diameter $5 \mathrm{~mm}$ ) was picked with the help of sterile cork borer and placed at the centre of a PDA plate having a particular concentration of AgNP and the control plate. Radial growth was measured by averaging the horizontal and vertical measurements for four times at an interval of $48 \mathrm{~h}$ (Kumar et al., 2018).

\section{Results and Discussion}

Efficacy of silver nanoparticle AgNP at different concentrations was evaluated against $B$. sorokiniana and A. brassicicola. A significant impact was noticed on the inhibitory aspects of nanosized silver against pathogens $B$. sorokiniana and A. brassicicola in the present study. Earlier work has shown AgNP to possess a significant level of antimicrobial activity in them (Jo et al., 2009; Kim et al., 2009; Ouda, 2014). AgNP is known to penetrate easily into the microbial cells of fungi implying lower concentrations of AgNP to be sufficient for antimicrobial activity (Samuel and Guggenbichler, 2004). Experimental work in this regard for testing in-vitro efficacy of silver nanoparticle against Saccharomyces cerevisiae revealed silver nanoparticle to be more effective than the regular fungicide in restricting fungal growth under laboratory conditions (Nasrollaha et al., 2010). Silver is known to attack a broad range of biological processes in microorganisms including alteration in cell membrane structure and functions (McDonnell et al., 1999); hence the nanosized silver due to its greater chemical reactivity finds it even easier in affecting microbial cells. The present work revealed the inhibitory impact of AgNP on spore germination as well as mycelial growth of pathogens B. sorokiniana and Alternaria brassicicola.

\section{Impact of AgNP on spore germination}

In general, lower germination percent was observed in B. sorokiniana when compared to A. brassicicola. Germination percent at four different concentrations of 10, 20, 50 and 100 ppm was noted at $24 \mathrm{~h}$ and $48 \mathrm{~h}$ of incubation for B. sorokiniana and A. brassicicola. For both the foliar pathogens, lower germination percent was recorded at $100 \mathrm{ppm}$ concentration of nanoparticle over control. Results revealed that $20 \mathrm{ppm}$ concentration of AgNP is suitable for germination test of $B$. sorokiniana considering a greater reduction in germinating spores (figure 1). The effect of AgNP on spore germination percent of $B$. sorokiniana was found to be non-significant between 20 and 100 ppm. Earlier experiments revealed AgNP to possess antifungal activity at $24 \mathrm{~h}$ after inoculation which states that direct contact of silver with the spores is critical in disease development (Young et al., 2009). As compared to the other three, AgNP at $20 \mathrm{ppm}$ concentration was observed to be most effective in reducing the germination percent of $A$. brassicicola (figure 2). Also, $\mathrm{AgNP}$ at $10 \mathrm{ppm}$ concentration was seen to be least effective in this case. However, the least significant difference between 50 and 100 ppm of AgNP was observed in reducing the germinating spores of $A$. brassicicola. Hence, while targeting a greater reduction in germinating spores of $A$. brassicicola, AgNP at a concentration of $20 \mathrm{ppm}$ may be considered. Lower level of germination percent of spores suggests the fact for employing nanoparticles to restrict the spore germination of pathogens, paving scope for control at the primary level of infection. 


\section{Effect of AgNP on mycelial growth}

In order to find out the effect of AgNP on the mycelial growth of both the foliar pathogens $B$. sorokiniana and A. brassicicola, poisoned food assay was conducted. All the four concentrations of AgNP revealed lower radial growth of the mycelia when compared to control. Radial growth was measured at 48, 96, 144 and 192 hour after inoculation (hai). For determining significance, last observation i.e. 192 hai was considered for the purpose of analysing the deviation in radial growth of the fungal culture, the reason being the slowgrowing character of the fungus. The larger mycelial colony was visualised on control plates as compared to the other four concentrations for both pathogens. AgNP at 100 ppm concentration revealed a maximum reduction in mycelia growth of $B$. sorokiniana (figure 3). This result is in agreement with Mishra et al., (2014) who showed biosynthesized AgNP is effective to inhibit mycelial growth of $B$. sorokiniana causing spot blotch in wheat. However, no significant difference was seen among 10, 20 and 50 ppm concentration of AgNP in reducing the mycelial growth of $B$. sorokiniana. Further, Alternaria brassicicola was reported for maximum restricted mycelia when applied with 100 ppm AgNP concentration (figure 4). The result agrees with an earlier experiment of reduced fungal hyphae of Alternaria alternata and Botrytis cinerea on the application of AgNP at a concentration of 15 ppm. In the same manner as earlier in $B$. sorokiniana, A. brassicicola too was found to exhibit least significant difference among 10, 20 and 100 ppm concentration of AgNP in reducing the mycelial growth of fungus.

Further, the observation of mycelial growth inhibition of both the pathogens, at 100 ppm of AgNP, is in agreement with the work done by Kim et al., (2012) who reported that AgNP effectively manages mycelial growth of pathogen at $25 \mathrm{ppm}$. Another experiment in this regard reported silver nanoparticle at 6 , $10,12,14$ and $16 \mathrm{ppm}$ concentration to completely inhibit the growth of Pythium aphanidermatum and Sclerotinia sclerotiorum (Mahdizadeh et al., 2014). The lower mycelial growth on nanoparticle applied plates suggests the implication of nanoparticles in effectively reducing the growth of fungus. Kim et al., (2009) observed AgNP inhibited the growth of fungal hyphae as well as conidial germination of Oak wilt pathogen Raffaelea sp suggesting antifungal activity of AgNP in damaging cell walls and fungal growth may be utilised in eradicating phytopathogens in future.

However, future studies regarding the time of application of nanoparticle as well as its concentration, biosynthesis of silver nanoparticle etc. needs to be stressed for effective use of nanoparticle in restricting the growth of fungus. In an experiment conducted earlier by Park et al., (2006) regarding the effective concentration of nanoparticle to be effective against pathogens, it was found that nanosized silica silver reported for 100 percent growth inhibition of Pythium ultimum, Magnaporthe grisea, Colletotrichum gloeosporioides, Botrytis cinerea and Rhizoctonia solani at $10 \mathrm{ppm}$. Similar strategies are needed to ponder for using AgNP as a class of nanofungicide against plant pathogens in future. Though, till today use of nanoparticle in the field of plant health management is limited to in vitro studies only, but future holds in it manifold unresolved questions regarding frequent application of nanoparticles for managing plant health.

Nanosized silver has the potential ability of rapid chemical reactions as against the metallic silver. Due to enhanced surface energy and surface area of silver at the nanoscale, it finds easy to penetrate microbial 
cells as against its bulk counterpart. As compared to the commercial fungicides available in the market, the nanotechnologically developed products are required in extremely less quantity to have a maximum possible impact in the shortest possible time (Ahmed A, 2015; Banik S and Sharma P, 2011; Chu et al., 2012). Further, overall, lower germination percent and higher mycelial inhibition percent at $100 \mathrm{ppm}$ observed in the present study on AgNP application demonstrates its applicability in the future for resisting the growth of the pathogen. Also, the results obtained in poisoned food technique further stresses on the fact to utilise and effectively develop AgNP for using it in the field of plant health management.

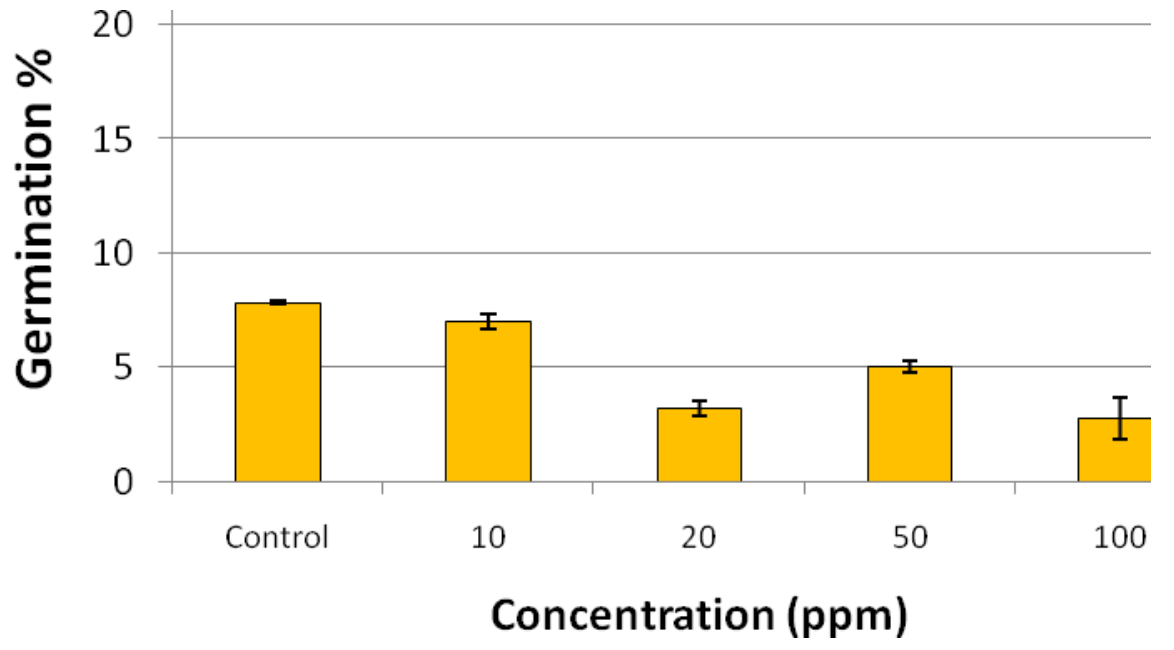

Figure.1 Germination percent of Bipolaris sorokiniana on silver (Ag)

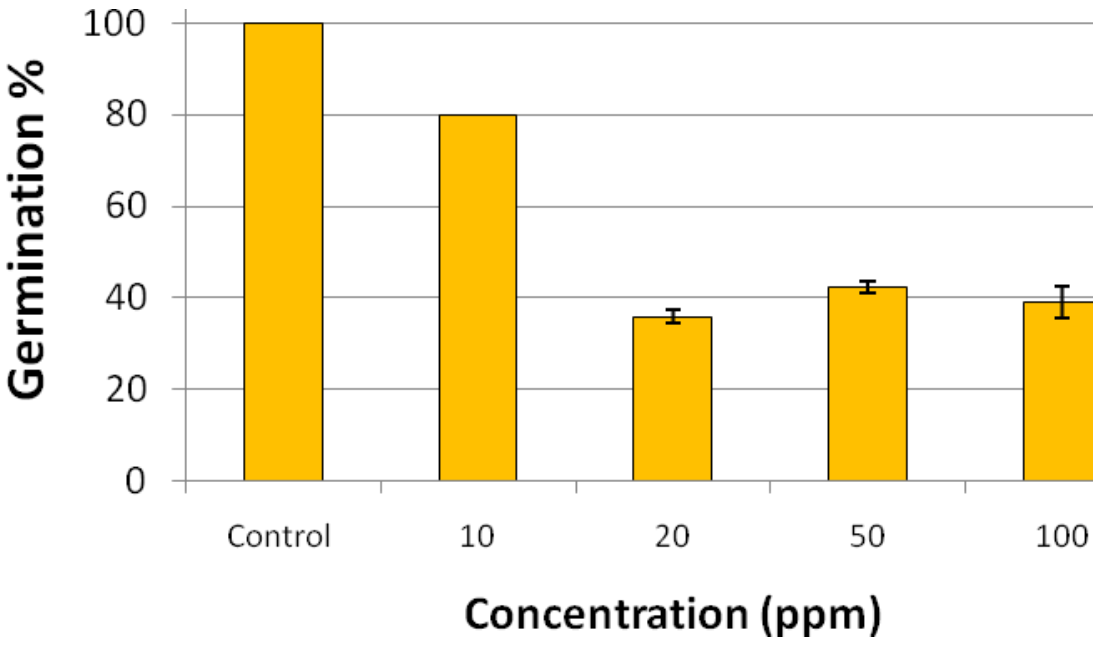

Figure.2 Germination percent of Alternaria brassicicola on silver (Ag) 


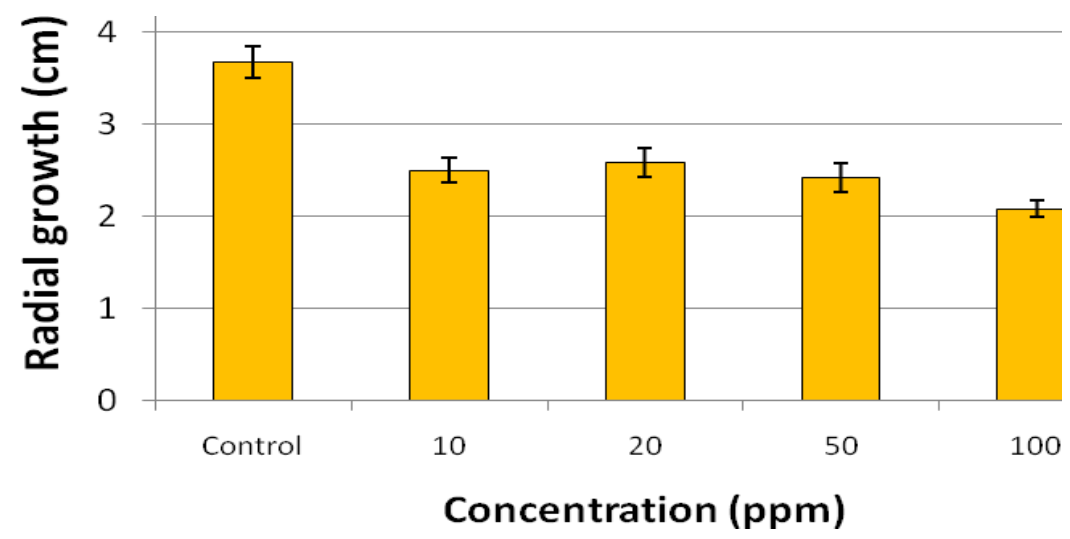

Figure.3 Mycelial growth on AgNP application in Bipolaris sorokiniana

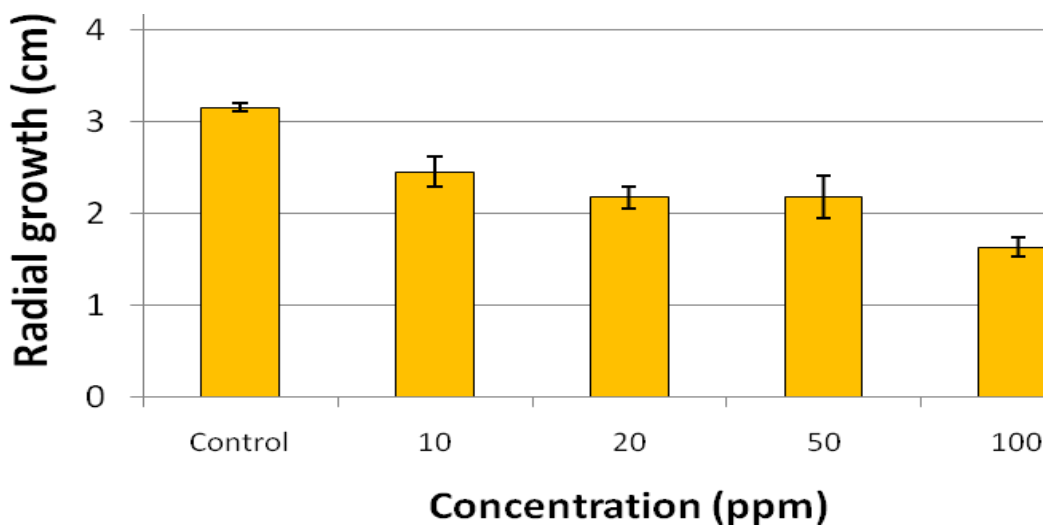

Figure.4 Mycelial growth on AgNP application in Alternaria brassicicola

\section{Acknowledgement}

This is a part of master's research work of AK. The funding of this work was received from a project $\mathrm{SP} / \mathrm{CP} / \mathrm{Rabi} / 2013-3$. This work was developed from BAU Communication Number 797/ 2020.

\section{References}

Ahmed, A I S. (2017). Chitosan and Silver nanoparticles as control agents of some Faba Bean spot diseases. Journal of Plant Pathology and Microbiology, 8: 421.

Banik, S., and Sharma, P. (2011). Plant pathology in the era of nanotechnology.
Indian Phytopathology, 64(2): 120-127.

Chu, H., Kim, HJ., Kim, MS., Yoon, BD., Park, HJ and Kim, CY. (2012). A nanosized Ag-silica hybrid complex prepared by $\gamma$-irradiation activates the defence response in Arabidopsis. Radiation Physics and Chemistry, 81: 180-184.

Crede, C S F. (1881). Die verhutung der augenentzundung derneugeboren. Arch Gynakol, 17: 50-53.

Gajbhiye, M., Keshareani, J., Ingle, A., Gade, A and Rai, M. (2009). Fungus-mediated synthesis of silver nanoparticles and their activity against pathogenic fungi in combination with fluconazole. Nanomedicine, 5(4): 382-6. 
Ghatak, A., Willocquet, L., Savary, S and Kumar, J. (2013). Variability in aggressiveness of rice blast (Magnaporthe oryzae) isolates originating from rice leaves and necks: A case of pathogen specialization? PLoS ONE, 8(6): e66180.

Jo, YK., Kim, BH and Jung, G. (2009). Antifungal activity of silver ions and nanoparticles on phytopathogenic fungi. Plant Disease, 93: 1037-1043.

Kim, WS., Jung, JH., Lamsal, K., Kim, YS., Min, JS and Lee, YS. (2012). Antifungal effects of silver nanoparticles (AgNP) against various plant pathogenic fungi. Microbiology. 40(1): 53-58.

Kim, SW., Kim, KS., Lamsal, K., Kim, YJ., Kim, SB, Jung, M., Sim, SJ., Kim, HS., Chang, SJ., Kim, JK and Lee, YS. (2009). An in vitro study of the antifungal effect of silver nanoparticles on oak wilt pathogen Raffaelea sp. $J$. Microbiol Biotechnol, 19(8): 760-764.

Kumar, R., Ghatak, A and Bhagat, AP. (2018). Assessing fungicides for seedling protection of cucumber to collar rot disease caused by Sclerotium rolfsii. International journal of plant protection, 11(1): 10-17.

Lamsal, K., Kim SW., Jung, JH., Kim, YS., Kim, KS and Lee YS. (2011). Application of silver nanoparticles for the control of Colletotrichum species in vitro and pepper anthracnose disease in field. Mycobiology, 39: 194-199.

Mahdizadeh, V., Safaie, N and Khelghatibana, F. (2014). Evaluation of antifungal activity of silver nanoparticles against some phytopathogenic fungi and Trichoderma harzianum. Journal of Crop Protection, 4(3): 291-300.

McDonnell, G. (1999). Antiseptics and disinfectants: activity, action and resistance. Clinical Microbiological Review, 12(1): 147-79.

Min, JS., Kim, KS., Kim, SW., Jung, JH., Lamsal, K., Kim, SB., Jung, MY and Lee, YS. (2009). Effects of colloidal silver nanoparticles on Sclerotiumforming phytopathogenic fungi. The Plant Pathol. J.

Mishra, S., Singh, BR., Singh, A., Keswani, C., Naqvi, AH and Singh, HB. (2014). Biofabricated silver nanoparticles act as a strong fungicide against Bipolaris sorokiniana causing spot blotch disease in wheat. PLoS ONE, 9: 5-e97881.

Nasrollahi, A., Pourshamsian, KH and Mansourkiaee, P. (2011). Antifungal activity of silver nanoparticles on some of fungi. Int $J$ of Nano Dimensio, 1(3): 233-239.

Ouda, S M. (2014). Antifungal activity of silver and copper nanoparticles on two plant pathogens, Alternaria alternata and Botrytis cinerea. Research Journal of Microbiology. 9(1): 34-42.

Park, HP, Kim, SH., Kim, HJ and Choi, HS. (2006). A New Composition of nanosized silica-silver for control of various plant diseases. Plant Pathology journal, 22(3): 295-302.

Ratyakshi., and Chauhan, RP. (2009). Colloidal synthesis of silver nano particles. Asian Journal of Chemistry, 21S: 113-116.

Samuel, U., and Guggenbichler, JP. (2004). Prevention of catheter related infections: the potential of a new nanosilver impregnated catheter. Int $J$. Antimicrobial Agents, 23S1: S75-S78.

Young, KJ., Kim, BH and Jung, G. (2009). Antifungal activity of silver ions and nanoparticles on Phytopathogenic Fungi. Plant Disease, 1037-1043. 


\section{How to cite this article:}

Aakanksha Kriti, Abhijeet Ghatak and Nintu Mandal. 2020. Inhibitory Potential Assessment of Silver Nanoparticle on Phytopathogenic Spores and Mycelial Growth of Bipolaris sorokiniana and Alternaria brassicicola. Int.J.Curr.Microbiol.App.Sci. 9(03): 692-699. doi: https://doi.org/10.20546/ijcmas.2020.903.083 